\title{
Pengaruh perendaman plat resin akrilik dalam larutan kopi dengan berbagai kekentalan terhadap perubahan volume larutan kopi
}

\author{
${ }^{1}$ Rachel S.Togatorop \\ ${ }^{2}$ Jimmy F.Rumampuk \\ ${ }^{3}$ Vonny N.S. Wowor
}

\author{
${ }^{1}$ Kandidat skripsi Program Studi Pendidikan Dokter Gigi \\ ${ }^{2}$ Bagian Fisika Fakultas Kedokteran Universitas Sam Ratulangi \\ ${ }^{3}$ Program Studi Pendidikan Dokter Gigi Fakultas Kedokteran Universitas Sam Ratulangi \\ Email: Racheliyaa111@gmail.com
}

\begin{abstract}
Acrylic resin is a denture base material that is still used in the field of dentistry. Porosity, one of the properties of a denture base material, can lead to absorption of fluid in the mouth, one of them is coffee. Porosity that occurs in a denture base material can cause discoloration. Coffee is favored by most people. Coffee contains tannins, a polyphenol compound, that can be absorbed through the porous of the denture base which can cause discoloration of the denture base. This study was aimed to determine the effect of acrylic resin plate immersed in coffee solution with various viscosity to the changes in volume of coffee solution. This was a pre laboratory experimental study with a pre and post test only control group design. Samples were 18 acrylic resin plates with a size of $65 \times 10$ x $2.5 \mathrm{~mm}$. Each treatment group consisted of 6 samples. The samples were divided into 3 treatment groups that were soaked in coffee $2 \mathrm{~g}, 4 \mathrm{~g}$, and $6 \mathrm{~g}$ for 7 days. The results showed that after 7 days of immersing resin acrylic plates in coffee solution with various viscosity, the changes of the volumes of coffee solution had a mean of 0.064 for $2 \mathrm{~g}$; 0.147 for $4 \mathrm{~g}$; and 0.244 for $6 \mathrm{~g}$. The one-way ANOVA test resulted in a $p$ value of 0.00 . Conclusion: There was a significant effect of resin acrylic immersed in a coffee solution with various viscosity to the changes in the volume of coffee solution.
\end{abstract}

Keywords: acrylic resin, changes in volume of the solution of coffee, coffee

\begin{abstract}
Abstrak: Resin akrilik merupakan bahan basis gigi tiruan yang sampai saat ini masih digunakan dalam bidang Kedokteran Gigi. Porositas merupakan salah satu sifat basis gigi tiruan. Adanya porositas pada basis gigi tiruan dapat mengakibatkan terserapnya cairan yang masuk dalam mulut salah satunya yaitu kopi. Porositas yang terjadi pada basis gigi tiruan dapat menyebabkan perubahan warna pada basis gigi tiruan. Kopi merupakan salah satu minuman yang banyak digemari masyarakat. Kopi mengandung tanin suatu senyawa polifenol yang dapat terserap masuk melalui porus pada basis gigi tiruan dan menyebabkan perubahan warna pada basis gigi tiruan. Penelitian ini bertujuan untuk mengetahui pengaruh perendaman plat resin akrilik dalam larutan kopi dengan berbagai kekentalan terhadap perubahan volume larutan kopi. Jenis penelitian ialah pra eksperimental laboratorium dengan pre and post test only control group design. Sampel terdiri dari 18 plat resin akrilik dengan ukuran 65 x $10 \times 2,5 \mathrm{~mm}$. Sampel dibagi menjadi 3 kelompok perlakuan yang di rendam dalam kopi $2 \mathrm{gr}$, 4gr, dan $6 \mathrm{gr}$ selama 7 hari. Masing-masing kelompok perlakuan terdiri dari 6 sampel. Hasil penelitian mendapatkan setelah 7 hari perendaman plat akrilik dalam larutan kopi dengan berbagai kekentalan terhadap perubahan volume larutan kopi memiliki rerata kopi 2 gr sebesar 0,064, kopi 4 gr sebesar 0,147. dan kopi 6 gr sebesar 0,244. Uji One-way Anova menunjukkan adanya pengaruh perendaman resin akrilik dalam larutan kopi dengan berbagai kekentalan terhadap perubahan volume larutan kopi dengan $p=0,00$. Simpulan: Terdapat pengaruh bermakna dari perendaman resin akrilik dalam larutan kopi dengan berbagai kekentalan terhadap perubahan volume larutan kopi
\end{abstract}

Kata kunci: resin akrilik, perubahan volume larutan kopi, kopi 
Basis gigi tiruan merupakan bagian dari gigi tiruan yang bersandar pada jaringan pendukung dan tempat bagi anasir gigi tiruan dilekatkan. Daya tahan dan sifat-sifat basis gigi tiruan sangat dipengaruhi oleh bahan basis gigi tiruan tersebut. Basis gigi tiruan dapat dibuat dari logam atau campuran logam, tetapi kebanyakan basis gigi tiruan dibuat menggunakan polimer seperti resin akrilik. ${ }^{1}$

Resin akrilik merupakan bahan basis gigi tiruan yang sampai saat ini masih digunakan dalam bidang kedokteran gigi. Lebih dari $95 \%$ basis gigi tiruan dibuat dari resin akrilik. ${ }^{2}$ Resin akrilik memiliki kelebihan yaitu warnanya harmonis dengan jaringan sekitarnya sehingga memenuhi faktor estetik, dapat dilapisi dan dicekatkan kembali dengan mudah, relatif lebih ringan, teknik pembuatan dan pemolesannya mudah, serta harganya relatif murah. Meskipun resin akrilik mempunyai kelebihan, namun resin akrilik juga memiliki kekurangan.

Kekurangan resin akrilik yaitu memiliki kekuatan dan kekerasan yang rendah sehingga tidak jarang basis dapat retak atau bahkan fraktur, penghantar termis yang buruk, mudah terjadi abrasi pada saat pembersihan atau pemakaian. Walaupun dalam derajat yang kecil, namun resin akrilik juga dapat menyerap cairan yang masuk ke dalam mulut mengingat resin jenis ini juga memiliki sifat porositas. ${ }^{3}$ Porositas pada basis gigi tiruan dapat terjadi karena adanya gelembung/porositas yang ada pada permukaan plat resin akrilik yang dapat mempengaruhi sifat fisis dari resin akrilik.

Adanya porositas pada basis gigi tiruan dapat mengakibatkan terserapnya cairan yang masuk dalam mulut salah satunya yaitu kopi. Porositas yang terjadi pada basis gigi tiruan dapat menyebabkan perubahan warna pada basis gigi tiruan. Suatu gigi tiruan yang ideal seharusnya memiliki warna yang mendekati warna alami. Perubahan warna basis gigi tiruan dapat disebabkan oleh faktor intrinsik dan faktor ekstrinsik. Faktor intrinsik adalah perubahan kimia pada bahan itu sendiri, yaitu proses polimerisasi yang tidak sempurna, ${ }^{4}$ sedangkan faktor ekstrinsik berupa faktor dari luar yaitu perubahan warna. Faktor ekstrinsik berupa kebiasaan mengonsumsi minuman seperti teh, kopi, wine atau minuman lainnya yang mengandung zat pewarna. ${ }^{2}$

Kopi merupakan salah satu minuman yang banyak digemari masyarakat termasuk masyarakat kota Manado. Dewasa ini diperkirakan tingkat konsumsi kopi di Indonesia telah mencapai 800 gram/kapita/tahun (AEKI, 2011). ${ }^{3}$ Kopi banyak digemari karena mempunyai efek dapat mengurangi kelelahan. Kandungan kafein dalam kopi berfungsi sebagai senyawa perangsang yang bersifat bukan alkohol. Pada sistem syaraf pusat, kafein berpengaruh dalam mencegah rasa kantuk dan dapat mengurangi rasa lelah. Kopi telah dikonsumsi dari generasi ke generasi, oleh sebab itu warung kopi banyak terdapat di berbagai tempat. Kopi biasanya dikonsumsi 3-4 gelas perhari. ${ }^{5}$ Biasanya penikmat kopi mulai dari usia remaja hingga lanjut usia.

Seiring bertambah usia pada seseorang, risiko kehilangan gigi semakin banyak. Pada pengguna gigi tiruan lepasan akrilik yang sering mengonsumsi kopi dalam jangka waktu yang lama, cairan kopi dapat terserap dan tertinggal dalam ronggarongga porositas pada basis gigi tiruan yang dapat menimbulkan perubahan warna pada basis gigi tiruan yang digunakan. Pada uumnya basis gigi tiruan memerlukan periode selama 17 hari untuk menjadi jenuh dengan air. Dari hasil klinik menunjukkan bahwa penyerapan air yang berlebihan dapat menyebabkan diskolorisasi. Kopi mengandung berbagai macam senyawa, antara lain tanin yang merupakan senyawa polifenol. Tanin biasanya ditemui pada beberapa tanaman dan jumlahnya juga berbeda-beda. Senyawa tanin yang ada di dalam kopi masuk melalui porositas pada basis gigi tiruan sehingga dapat menyebabkan perubahan warna kecoklatan pada suatu basis gigi tiruan. ${ }^{6}$

Penelitian ini bertujuan untuk mengetahui pengaruh perendaman resin 
akrilik dalam minuman kopi dengan berbagai kekentalan terhadap perubahan volume larutan kopi yang terjadi karena adanya porositas.

\section{BAHAN DAN METODE PENELITIAN}

Jenis penelitian ini adalah eksperimental laboratorium dengan jenis penelitian pre and post-test control group design. Alat yang digunakan dalam penelitian terdiri dari: Spectrofotometer, kuvet (membuat plat akrilik), alat press (membuat plat akrilik), pisau gips, pisau malam, kertas gosok, penggaris, alat tulis menulis, rubber bowl, spatula, kompor, straigh hand piece (memoles akrilik), bur poles, panci aluminium, gelas ukur untuk mengukur volume air, botol kaca untuk merendam plat akrilik, kamera, timbangan digital (untuk mengukur berat bubuk kopi), mixxingjar. Bahan yang digunakan dalam penelitian ini yaitu: malam merah ukuran $65 \times 10 \times 2,5 \mathrm{~mm}$, powder akrilik polimerisasi panas, liquid akrilik polimerisasi panas, dental stone (gips), CMS, air, bubuk kopi. Sampel yang digunakan dalam penelitian ini sebanyak 18 sampel yang berukuran $65 \times 10 \times 2,5 \mathrm{~mm}$. Larutan kopi yang digunakan dalam penelitian ini didapatkan dengan mencampurkan bubuk kopi nescafe murni dengan air panas sebanyak $150 \mathrm{ml}$.

Perendaman sampel dalam larutan kopi dilakukan selama 7 hari. Delapan belas plat resin akrilik di rendam terlebih dahulu dalam masing-masing larutan kopi $2 \mathrm{gr}, 4 \mathrm{gr}$, dan $6 g r$ kemudian diukur nilai awal perubahan volume larutan kopi, setelah itu dilanjutkan dengan merendam delapan belas akrilik yang sama kedalam masingmasing larutan kopi selama 7 hari kemudian larutan diukur untuk melihat nilai akhir perubahan volume larutan kopi. Alat yang digunkaan untuk mengukur perubahan volume larutan kopi yaitu spectrofotometer di Laboratorium FMIPA Universitas Sam Ratulangi. Hasil penelitian ini kemudian dianalisa menggunakan uji statistik One Way Anova.

\section{HASIL PENELITIAN}

Hasil penelitian disajikan dalam bentuk Tabel sebagai berikut:

Tabel 1. Nilai perubahan volume larutan kopi diukur dengan spektrofotometer

\begin{tabular}{cccc}
\hline & & \multicolumn{2}{c}{ Nilai Absorbansi } \\
\hline Kopi & Sampel & Sebelum & Sesudah \\
\hline \multirow{6}{*}{2 gr } & 1 & 0,001 & 0,070 \\
& 2 & 0,025 & 0,053 \\
& 3 & 0,022 & 0,066 \\
& 4 & 0,001 & 0,070 \\
& 5 & 0,014 & 0,062 \\
& 6 & 0,014 & 0,062 \\
4 gr & 1 & 0,081 & 0,143 \\
& 2 & 0,083 & 0,182 \\
& 3 & 0,043 & 0,136 \\
& 4 & 0,048 & 0,152 \\
6 gr & 5 & 0,070 & 0,137 \\
& 1 & 0,048 & 0,133 \\
& 2 & 0,015 & 0,245 \\
& 3 & 0,025 & 0,216 \\
& 4 & 0,025 & 0,205 \\
& 5 & 0,004 & 0,276 \\
& 6 & 0,007 & 0,276 \\
& & 0,007 & 0,243 \\
\hline
\end{tabular}

Tabel 2. Rata-rata nilai perubahan volume larutan kopi

\begin{tabular}{ccc}
\hline Larutan kopi & Sebelum & Sesudah \\
\hline $2 \mathrm{gr}$ & 0,013 & 0,064 \\
$4 \mathrm{gr}$ & 0,062 & 0,147 \\
$6 \mathrm{gr}$ & 0,014 & 0,244 \\
\hline
\end{tabular}

Tabel 3. Uji Normalitas Menggunakan Shapiro-Wilk

\begin{tabular}{cccc}
\hline $\begin{array}{c}\text { Larutan } \\
\text { kopi }\end{array}$ & \multicolumn{3}{c}{ Shapiro Wilk } \\
\hline & Statistik & df & Sig. \\
2 gr & 0,89 & 6 & 0,34 \\
4 gr & 0,91 & 6 & 0,45 \\
6 gr & 0,90 & 6 & 0,41 \\
\hline
\end{tabular}

Uji homogenitas dilakukan untuk melihat apakah tiap kelompok mempunyai varian yang sama. Hasil yang didapat dari pengujian homogenitas ialah nilai levene statistic 2,903 yang menunjukkan bermakna dengan nilai probabilitas 0,086 . Oleh karena nilai probabilitas $p>0,05$ berarti bahwa ketiga varian berefek sama. 
Tabel 4. Uji One Way Anova perubahan volume larutan kopi

\begin{tabular}{ccccc}
\hline $\begin{array}{c}\text { Larutan } \\
\text { kopi }\end{array}$ & $\begin{array}{c}\text { Sig. } \\
\text { (Post Hoc) }\end{array}$ & Df. & F & Sig. \\
\hline 2gr dan 4gr & .114 & & & \\
2gr dan 6gr & .000 & 18 & 80.532 & .000 \\
4gr dan 6gr & .000 & & & \\
\hline
\end{tabular}

\section{BAHASAN}

Pada penelitian ini didapatkan hasil rata-rata nilai perubahan volume larutan kopi yang diukur dengan menggunakan spectrofotometer sebelum perlakuan dan sesudah perlakuan yaitu pada kelompok larutan kopi 2 gr memiliki nilai absorbansi yang paling rendah sedangkan kelompok larutan kopi 6 gr memiliki nilai absorbansi yang paling tinggi (Tabel 2).

Tabel 3 menunjukkan adanya nilai signifikan yang dilakukan pada uji normalitas Shapiro-Wilk. Nilai kelompok larutan kopi 2 gr mempunyai nilai $\mathrm{p}=0,34$ (p>0,05), kelompok larutan kopi 4 gr didapat nilai $p=0,45 \quad(p>0,05)$, dan kelompok larutan kopi 6 gr didapat nilai $\mathrm{p}=$ $0,41(p>0,05)$ yang berarti bahwa nilai dari tiap-tiap kelompok terdistribusi secara normal. Setelah data terdistribusi normal kemudian dilanjutkan dengan uji homogenitas dan didapatkan bahwa nilai levene statistic 2,903 menunjukkan bermakna dengan nilai probabilitas 0,086 . Oleh karena nilai probabilitas $\mathrm{p}>0,05$ artinya bahwa ketiga varian adalah sama. Tabel homogenitas dapat dilihat pada lembar lampiran. Pada Tabel 4 dilanjutkan dengan uji One Way Anova untuk melihat perbandingan rata-rata nilai antar kelompok perlakuan dimana hasil perhitungan menggunakan uji One Way Anova menunjukkan bahwa nilai yang didapat signifikan $0,00 \quad(\mathrm{p}<0,05)$, artinya bahwa terdapat pengaruh perendaman plat akrilik dalam larutan kopi dengan berbagai kekentalan terhadap perubahan volume larutan kopi $(\mathrm{p}<0,05)$.

Perubahan volume larutan kopi dapat memberi dampak pada perubahan warna plat resin akrilik yang berarti berkurangnya volume larutan kopi dikarenakan adanya larutan kopi yang masuk dan terserap melalui pori-pori/rongga pada plat akrilik. Semakin lama plat akrilik berkontak dengan suatu larutan maka semakin banyak zat warna yang larut dalam air akan terserap kemudian mengendap pada bahan basis protesa tersebut. Perendaman yang cukup lama akan menyebabkan banyak molekul air yang mengandung zat warna masuk dalam pori-pori pada sampel sehingga berpengaruh terhadap perubahan warna resin termoplastik. ${ }^{6}$ Menurut Anusavice (2004) terjadinya proses penyerapan air pada resin akrilik heat cured secara difusi dengan cara molekul air menembus massa polimetal metakrilat dan menempati posisi di antara rantai polimer. Akibatnya rantai polimer yang terganggu dipaksa memisah. ${ }^{7}$

Perubahan volume larutan kopi dalam penelitian ini jugadapat terjadi karena adanya gelembung/porositas yang ada pada permukaan plat resin akrilik yang dapat mempengaruhi sifat fisis dari resin akrilik. Porositas cenderung terjadi pada bagian basis gigitiruan yang lebih tebal. Porositas disebabkan oleh karena penguapan monomer yang tidak bereaksi dan berat molekul polimer yang rendah, serta pengadukan yang tidak tepat antara komponen polimer dan monomer. Timbulnya porositas juga dapat terjadi karena adonan resin akrilik yang tidak homogen, penggunaan perbandingan polimer dan monomer yang kurang tepat, prosedur pengadukan yang tidak terkontrol dengan baik, serta waktu pengisian bahan ke dalam mould yang tidak tepat.

Pada penelitian ini, perubahan volume pada larutan kopi yang digunakan untuk merendam plat resin akrilik terjadi karena adanya satu kandungan senyawa dalam kopi yaitu senyawa tanin yang diketahui mengandung polifenol yang bersifat asam sehingga dapat menganggu reaksi hidrolisis antara fenol dan ester polimetil metakrilat pada plat resin akrilik sehingga terjadi banyak rongga atau porus pada permukaan plat resin akrilik. Hal ini menyebabkan adanya difusi cairan kopiyang masuk kedalam plat resin akrilik akibatnya terjadi perubahan volume larutan kopiyang dapat 
berakibat pada perubahan warna pada plat resin akrilik karena terjadi peningkatan absorbsi zat tanin. ${ }^{8}$

Hasil penelitian dan hasil uji statistik One Way Anova menunjukkan bahwa terdapat perubahan volume larutan kopi pada perendaman plat resin akrilik dalam larutan kopi secara bermakna $(\mathrm{p}=0,00)$ antara larutan kopi yang kurang kental, kental dan sangat kental selama perendaman 7 hari.

\section{SIMPULAN}

Dari hasil penelitian yang dilakukan di Laboratorium FMIPA Universitas Sam Ratulangi dapat disimpulkan bahwa terdapat pengaruh bermakna dari perubahan volume larutan kopi dengan berbagai kekentalan yang digunakan untuk merendam plat akrilik.

\section{SARAN}

1. Disarankan agar pemerintah dalam hal ini dinas kesehatan untuk menggunakan informasi dalam penelitian ini untuk promosi kesehatan dan menyarankan kepada pengguna gigi tiruan agar mengurangi konsumsi kopi yang dapat berdampak pada perubahan warna basis gigi tiruan.

2. Perlu dilakukan penelitian selanjutnya mengenai pengaruh perendaman plat akrilik dalam larutan kopi terhadap perubahan warna plat akrilik.

3. Perlu dilakukan penelitian mengenai cara menghilangkan stain kopi pada plat akrilik basis gigi tiruan.

\section{DAFTAR PUSTAKA}

1.Dewi LS. Perubahan warna pada basis gigi tiruan resin akrilik polimerisasi panas setelah perendaman dalam minuman soda [Skripsi] Medan: Universitas Sumatera Utara; 2011.

2.Lisastro EZM. Pengaruh perendaman basis gigi tiruan resin akrilik dalam larutan ekstrak daun saga terhadap perubahan warna basis [Skripsi]. Makassar: Universitas Hasanuddin; 2015.

3.Neormansyah $W$. Pengaruh perendaman basis gigi tiruan resin akrilik polimerisasi panas dalam larutan kopi dan teh terhadap kekuatan Impak dan Transversal [Skripsi]. Medan: Universitas Sumatera Utara; 2014.

4.Said SPU. Pengaruh lama perendaman bahan gigi tiruan resin nilon termoplastik dalam minuman teh terhadap stabilitas warna [Skripsi]. Makassar: Universitas Hasanuddin; 2015.

5.Maramis RK. Analisis kafein dalam kopi bubuk di kota Manado menggunakan Spektrofotometri UV-VIS. Journal Ilmiah Farmasi. 2013;2(04):122-6.

6.Ulynnuha M. Pengaruh lama perendaman nilon termoplastik dalam minuman kopi robusta terhadap perubahan warna nilon termoplastik [Skripsi]. Yogyakarta: Universitas Muhammadiyah Yogyakarta; 2012.

7.Dinar SP. Pengaruh multi konsentrasi ekstrak teh hijau (cammelia sinesis) terhadap perubahan warna resin akrilik heat cured serat kaca $1 \%$. Yogyakarta: Universitas Muhammadiyah Yogyakarta; 2012

8.Baga I, Handajani S, Putri AR. Efek lama perendaman resin akrilik heat cured dalam minuman teh hijau (Camellia Sinensis) terhadap perubahan warna. Malang: Universitas Brawijaya. 